\title{
Erratum to: Production of isobutanol from crude glycerol by a genetically-engineered Klebsiella pneumoniae strain
}

\author{
Baek-Rock Oh $\cdot$ Sun-Yeon Heo $\cdot$ Sung-Mok Lee $\cdot$ Won-Kyung Hong • \\ Jang Min Park • You Ree Jung • Dae-Hyuk Kim • Jung-Hoon Sohn • \\ Jeong-Woo Seo $\cdot$ Chul Ho Kim
}

Published online: 25 October 2013

(C) Springer Science+Business Media Dordrecht 2013

\begin{abstract}
Klebsiella pneumoniae was engineered to produce isobutanol from crude glycerol as a sole carbon source by expressing acetolactate synthase (ilvIH), ketoacid reducto-isomerase (ilvC) and dihydroxy-acid dehydratase $(i l v D)$ from $K$. pneumoniae, and $\alpha$-ketoisovalerate decarboxylase (kivd) and alcohol dehydrogenase (adhA) from Lactococcus lactis. Engineered $K$. pneumonia, $\Delta l d h A / \mathrm{pBR}-\mathrm{iBO}$ (ilvIH-ilvC-ilvD-kivd$a d h A)$, produced isobutanol (160 $\left.\mathrm{mg}^{-1}\right)$ from crude glycerol. To increase the yield of isobutanol, we eliminated the 2,3-butanediol pathway from the recombinant strain by inactivating $\alpha$-acetolactate
\end{abstract}

Electronic supplementary material The online version of this article (doi:10.1007/s10529-013-1383-3) contains supplementary material, which is available to authorized users.

The original paper contained an inadvertent error. Regretfully, the compound named as "2-butanol" was incorrect and should have been given as "isobutanol". We apologise to the authors for making this error. The article re-published in the following pages is therefore the correct version of this paper.

The online version of the original article can be found under doi:10.1007/s10529-013-1333-0.

B.-R. Oh · S.-Y. Heo · S.-M. Lee · W.-K. Hong ·

J. M. Park · Y. R. Jung · J.-W. Seo · C. H. Kim ( $\square)$

Applied Microbiology Research Center, Bio-Materials

Research Institute, Korea Research Institute of Bioscience

and Biotechnology (KRIBB), Jeongeup,

Jeonbuk 580-185, South Korea

e-mail: kim3641@kribb.re.kr decarboxylase $(a d c)$. This further engineering step improved the yield of isobutanol from 160 to $320 \mathrm{mg}^{-1}$. This represents the first successful attempt to produce isobutanol from crude glycerol.

Keywords Crude glycerol - Genetic engineering · Isobutanol $\cdot$ Klebsiella pneumoniae

\section{Introduction}

During biodiesel production, crude glycerol is formed in bulk as a major by-product and can represent as much as $10 \%(\mathrm{w} / \mathrm{w})$ of the biodiesel generated (Johnson et al. 2007). This surplus of crude glycerol has had a deleterious effect on the

\section{D.-H. Kim}

Institute for Molecular Biology and Genetics, Research

Center of Bioactive Materials, Chonbuk National

University, Jeonju, Jeonbuk 561-756, South Korea

\section{J.-H. Sohn}

Systems and Synthetic Biology Research Center, Korea Research Institute of Bioscience and Biotechnology (KRIBB), Taejon 305-333, South Korea 
traditional market for glycerol and has created a significant environmental problem because glycerol cannot be discharged directly into the environment without treatment (da Silva et al. 2009). Glycerol has been considered a low-cost feedstock for industrial value-added products. In addition to being cheap and abundant, glycerol is more reduced than sugars, and thus can be used to obtain reduced, value-added products (Dharmadi et al. 2006).

Isobutanol is a valuable, advanced biofuel with superior performance and economics. In addition, it has a higher octane number, lower hygroscopicity and higher energy density than ethanol, and the same capabilities as gasoline (Connor and Liao 2011; Lee et al. 2012). Notably, when isobutanol is converted to 2-butylene, it can serve as a precursor for a number of value-added products, such as terephthalic acid, used in the syntheses of polyester and other bioplastics (Potera 2009; Curran et al. 2013).

Metabolic engineering is used to enhance the microbial production of value-added products (Strohl 2001). The general design approach for enhancing the yield of such products is to overexpress elements of the corresponding biosynthetic pathway and delete components of competing pathways (Gonzalez et al. 2008; Durnin et al. 2009; Smith and Liao 2011; Curran et al. 2013). Isobutanol production from glucose has been reported using genetically-engineered microorganisms: an Escherichia coli strain was engineered by deleting several genes involved in competing pathways and overexpressing acetolactate synthase (AlsS) from Bacillus subtilis, ketol-acid reductoisomerase-dihydroxyacid dehydratase (IlvC-IlvD) from E. coli, alpha-ketoisovalerate decarboxylase (kivd) from Lactococcus lactis, and alcohol dehydrogenase (adh2p) from Saccharomyces cerevisiae; the resulting strain produced $22 \mathrm{~g}$ isobutanol $1^{-1}$ from glucose (Atsumi et al. 2008). Lee et al. (2012) reported the production of isobutanol $\left(151 \mathrm{mg}^{-1}\right)$ from glucose by $S$. cerevisiae through overexpression of Kivd and valine biosynthetic enzymes (acetolactate synthase, acetohydroxyacid reductoisomerase, and dihydroxyacid dehydratase).

Here, we describe the first construction of a microbial system for the production of isobutanol from glycerol using $K$. pneumoniae, a well-known glycerol-fermenting microorganism. The genetic stability of the engineered $K$. pneumoniae was also investigated.

\section{Materials and methods}

Bacterial strains, plasmids, and media

Klebsiella pneumoniae $\triangle l d h A$ mutant, derived from ATCC 200721, has been described (Oh et al. 2012a). Escherichia coli DH5 $\alpha$ was used for DNA manipulation. Lamda Red and FLP recombinases were expressed by helper plasmids pKD46 (Datsenko and Wanner 2000) and pCP20 (Cherepanov and Wackernagel 1995), respectively; replication of these plasmids is temperature-sensitive and the plasmids can thus be easily eliminated. The pIJ773 vector was the source of the apramycin-resistance gene. Microbial cells were grown in LB medium [yeast extract (Difco), $0.5 \%$ (w/v); Bacto-tryptone (Difco), $1 \%(\mathrm{w} / \mathrm{v})$; and $\mathrm{NaCl}, 1 \%$ (w/v)] or Germ medium (Oh et al. 2011), supplemented with antibiotic $(10 \mu \mathrm{g}$ tetracycline $\mathrm{ml}^{-1}$ ). Germ medium contained $20 \mathrm{~g}$ crude glycerol $\mathrm{l}^{-1}, 2 \mathrm{~g}\left(\mathrm{NH}_{4}\right)_{2} \mathrm{SO}_{4} \mathrm{l}^{-1}, 3.4 \mathrm{~g} \mathrm{~K}_{2} \mathrm{HPO}_{4} \mathrm{l}^{-1}, 1.3 \mathrm{~g}$ $\mathrm{KH}_{2} \mathrm{PO}_{4} \mathrm{l}^{-1}, 0.2 \mathrm{~g} \mathrm{MgSO}_{4} \mathrm{l}^{-1}, 0.02 \mathrm{~g} \mathrm{CaCl}_{2} \cdot 2 \mathrm{H}_{2} \mathrm{O}$ $\mathrm{1}^{-1}, 1 \mathrm{~g}$ yeast extract $\mathrm{l}^{-1}, 1 \mathrm{ml} \mathrm{Fe}$ solution [5 $\mathrm{g}$ $\mathrm{FeSO}_{4} \cdot 7 \mathrm{H}_{2} \mathrm{O}^{-1}$ and $4 \mathrm{ml} \mathrm{HCl}\left(37 \%\right.$, w/v) $\mathrm{l}^{-1}$ ], and $1 \mathrm{ml}$ trace element solution $\left[70 \mathrm{mg} \mathrm{ZnCl}{ }_{2} 1^{-1}, 100 \mathrm{mg}\right.$ $\mathrm{MnCl}_{2} \cdot 4 \mathrm{H}_{2} \mathrm{O} \mathrm{l}^{-1}, 60 \mathrm{mg} \mathrm{H} \mathrm{BO}_{3} \mathrm{l}^{-1}, 200 \mathrm{mg} \mathrm{CoCl}$ $4 \mathrm{H}_{2} \mathrm{Ol}^{-1}, 20 \mathrm{mg} \mathrm{CuCl}{ }_{2} \cdot 2 \mathrm{H}_{2} \mathrm{Ol}^{-1}, 25 \mathrm{mg} \mathrm{NiCl}{ }_{2} \cdot 6 \mathrm{H}_{2} \mathrm{O}$ $\mathrm{l}^{-1}, 35 \mathrm{mg} \mathrm{Na} \mathrm{MoO}_{4} \mathrm{l}^{-1} \cdot 2 \mathrm{H}_{2} \mathrm{O}$, and $4 \mathrm{ml} \mathrm{l}^{-1} \mathrm{HCl}$ $(37 \%, \mathrm{w} / \mathrm{v})]$. Crude glycerol (purity $80 \%$, w/w) was obtained from a biodiesel-producing company (GS Bio, Yeosu, Korea).

Construction of recombinant plasmids

A schematic representation of the strategy used to construct pBR-iBO is shown in Supplementary Fig. 1. The lac $Z$ promoter sequence $\left(\mathrm{P}_{\text {lac }}\right.$-ilvIH $)$ was amplified using the primer pair $\mathrm{P}_{\text {lac }}$-ilvIH-F (5'-AGC GGG CAG TGA GCG CAA- $\left.3^{\prime}\right)$ and $\mathrm{P}_{\text {lac }}$-ilvIH-R (5'-ACT AGT AGC TGT TTC CTG TGT GAA ATT G- $3^{\prime}$ ); underlined bases indicate a SpeI site. The open reading frames of the following genes were amplified from chromosomal DNA of K. pneumoniae MGH78578 (ATCC 200721) and L. lactis using the primers shown in Supplementary Table 1: acetolactate synthase (K. pneumoniae ilvIH; ABR75542.1 and ABR75543.1), keto-acid reductoisomerase (K. pneumoniae ilvC; ABR79645.1), dihydroxyacid dehydratase (K. pneumoniae ilvD; ABR79642.1), alpha-ketoisovalerate decarboxylase (L. lactis kivD; CAG34226.1), and alcohol dehydrogenase (L. lactis 
adhA; AAK05905.1). Amplified DNA fragments were cloned into the pGEM TEasy vector (Promega, Madison, WI, USA), followed by nucleotide sequencing to confirm that no errors were introduced during cloning. A SpeI$X b a I$ fragment containing the $i l v I H$ gene was next inserted into the corresponding restriction sites downstream of the lac $Z$ promoter sequence (pGEM-ilvIH). pGEM-P ${ }_{\text {lac }}$-ilvIH-ilvC-ilvD-kivd-adh was generated by sequentially inserting NheI-SpeI fragments containing ilvC (pGEM-ilvC), ilvD (pGEM-ilvD), kivd (pGEMkivd), adhA (pGEM-adh) into SpeI sites of pGEM-ilvIH. Finally, pBR322 was cleaved with ScaI, treated with alkaline phosphatase, ligated with a DNA fragment obtained by digestion of pGEM-P $\mathrm{Pacz}^{-i l v I H-i l v C-i l v D-}$ kivd-adh with NotI, and then treated with Klenow fragment to yield plasmid pBR-iBO (ilvIH-ilvC-ilvD$k i v d-a d h)$. The final plasmid was transformed into $K$. pneumoniae strains by electroporation (Fournet-Fayard et al. 1995).

Deletion of the 2,3-butanediol (2,3-BD)

biosynthesis pathway

The chromosomal acetolactate decarboxylase gene $(a d c)$ involved in 2,3-BD biosynthesis (Supplementary Fig. 2) was deleted by first amplifying 0.3-kb DNA sequences upstream and downstream of $a d c$ by PCR using the primer pairs P1 (5'-ATC GAA AAC GTC TCA AAC CAG C $\left.-3^{\prime}\right)$ and P2 (5'-GAT CGT CGA GGA CGT CGG TCG TTA ACA TAG ACC TGA CTG CTG AAG G-3' for the upstream region and P3 (5'-CCT TCA GCA GTC AGG TCT ATG TTA ACG ACC GAC GTC CTC GAC GAT C-3') and P4 (5'-CCT TAA CTT TCT ACG GAA CGG A- $\left.3^{\prime}\right)$ for the downstream region (bases in italics indicate a $\mathrm{HpaI}$ site). The PCR conditions included an initial denaturation step at $95{ }^{\circ} \mathrm{C}$ for $5 \mathrm{~min}$, followed by 30 cycles of $95{ }^{\circ} \mathrm{C}$ for $30 \mathrm{~s}, 55^{\circ} \mathrm{C}$ for $30 \mathrm{~s}$ and $72{ }^{\circ} \mathrm{C}$ for $90 \mathrm{~s}$, with a final incubation at $72{ }^{\circ} \mathrm{C}$ for $7 \mathrm{~min}$. The PCR products were annealed using $\mathrm{P} 1$ and $\mathrm{P} 4$, and the resultant product was cloned into pGEM-T Easy. Next, an apramycin-resistance gene, $\operatorname{aac}(3) I V$, obtained from pIJ773 by digestion with EcoRI and HindIII, was inserted into the HpaI site of the PCR product following treatment with Klenow fragment. The resultant plasmid, designated pT-adc-Apra, was used as a template for PCR amplification of the deletion cassette, which was next introduced into
K. pneumoniae $\triangle l d h A$ by electroporation (FournetFayard et al. 1995). Correct integration of the DNA fragment by homologous recombination was confirmed by Southern hybridization using the upstream regions of $a d c$ and $a a c(3) I V$ to probe PstI-digested chromosomal DNA; the probes were labeled using the DIG (digoxigenin-dUTP) system (Roche Diagnostics $\mathrm{GmbH}$, Mannheim, Germany).

\section{Cultivation of $K$. pneumoniae strains}

Seed cells for fermentation were prepared in 11 flasks containing $200 \mathrm{ml}$ Germ medium. Flasks were incubated at $37{ }^{\circ} \mathrm{C}$ for $12 \mathrm{~h}$, and cultures were subsequently inoculated into growth vessels at $10 \%(\mathrm{v} / \mathrm{v})$. Batch fermentations were conducted in 51 stirredvessel systems (Kobiotech Co. Ltd., Incheon, Korea) containing 21 germ medium; all fermentation experiments were at $37{ }^{\circ} \mathrm{C}$ with stirring at $200 \mathrm{rpm}$ and an airflow rate of $0.5 \mathrm{vvm}$. IPTG was added to cultures at $0.5 \mathrm{mM}$ to induce the expression of genes. All data are average of three independent experiments.

Analytical methods

Concentrations of crude glycerol, 1,3-propanediol (1,3-PD), ethanol, acetate, lactate, succinate, and 2,3-BD were determined using HPLC equipped with a refractive index detector and an organic acid analysis column $(300 \times 78 \mathrm{~mm}$, Aminex HPX- $87 \mathrm{H}$; Bio$\mathrm{Rad})$. The mobile phase was $5 \mathrm{mM} \mathrm{H}_{2} \mathrm{SO}_{4}$ at $0.8 \mathrm{ml} \mathrm{min}^{-1}$. Column and cell were at $65{ }^{\circ} \mathrm{C}$ and $45^{\circ} \mathrm{C}$, respectively (Oh et al. 2012a). Isobutanol was determined using GC equipped with a ZB-WAX plus column (Phenomenex). The column was controlled according to the following gradient program: $50{ }^{\circ} \mathrm{C}$ for $1 \mathrm{~min}$; then increasing at $15^{\circ} \mathrm{C} \mathrm{min}^{-1} ; 225^{\circ} \mathrm{C}$ for 5 min. Biomass concentration was determined from the $\mathrm{OD}_{600}$ value.

\section{Results and discussion}

Isobutanol production from crude glycerol by $K$. pneumoniae $\Delta l d h A$ harboring $\mathrm{pBR}-\mathrm{iBO}$

To produce isobutanol from glycerol, we constructed the plasmid pBR-iBO containing genes constituting 


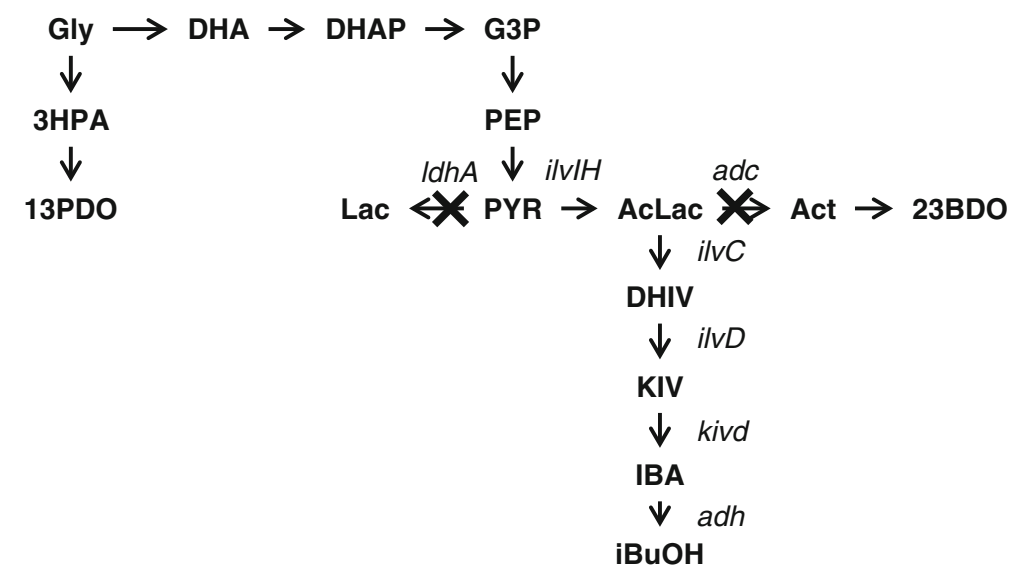

Fig. 1 Genetic engineering steps used to construct a microbial system for producing isobutanol from glycerol. Gly glycerol, $D H A$ dihydroxyacetone, DHAP dihydroxyacetone phosphate, $G 3 P$ glycerol 3-phosphate, PEP phosphoenol pyruvate, $P Y R$ pyruvate, Lac lactate, AcLac acetolactate, Act acetoin, 2,3BD 2,3-butanediol, DHIV dihydroxy isovaleric acid, KIV $\alpha$ -

Table 1 Analysis of glycerol fermentation metabolites in $K$. pneumoniae strains

\begin{tabular}{lllll}
\hline $\begin{array}{l}\text { Metabolites } \\
\left(\mathrm{g} \mathrm{l}^{-1}\right)\end{array}$ & $\begin{array}{l}\Delta l d h A / \\
\mathrm{pBR} 322\end{array}$ & $\begin{array}{l}\Delta l d h A / \\
\mathrm{pBR}- \\
\mathrm{iBO}\end{array}$ & $\begin{array}{l}\Delta l d h A \\
\Delta a d c l \\
\mathrm{pBR} 322\end{array}$ & $\begin{array}{l}\Delta l d h A \\
\Delta a d c / \\
\mathrm{pBR}-\mathrm{iBO}\end{array}$ \\
\hline Acetate & 0.5 & 0.5 & 0.8 & 0.4 \\
Ethanol & 1 & 1.1 & 1.4 & 1.3 \\
Isobutanol & 0 & 0.16 & 0 & 0.32 \\
1,3-Propanediol & 7.8 & 7.7 & 8.3 & 8 \\
Succinate & 0.4 & 0.5 & 0.6 & 0.6 \\
2,3-Butanediol & 2.3 & 1.9 & 0 & 0 \\
\hline
\end{tabular}

the biosynthesis pathway (ilvIH-ilvC-ilvD-kivd$a d h A$ ) and introduced it into the K. pneumoniae strain (Fig. 1), which is a typical glycerol-fermenting bacterium. Unfortunately, simply inserting this gene cassette into the wild-type $K$. pneumoniae strain was insufficient and isobutanol production was not detected (data not shown). When the recombinant plasmid pBRiBO was introduced into the lactate dehydrogenasedeficient $K$. pneumoniae $\Delta l d h A$ mutant, production of isobutanol from crude glycerol was detected (Table 1). Interestingly the production of isobutanol began upon cessation of growth of the mutant cells (Fig. 2). This stationary stage-specific production might be related to the high toxicity to isobutanol. Consistent with this, we found that the growth of $K$. pneumoniae cells was ketoisovalerate, IBA isobutyric acid, $i B u O H$ isobutanol, 3HPA 3-hydroxypropionaldehyde, 13PDO 1,3-propanediol, ldhA lactate dehydrogenase, $a d c$ acetolactate decarboxylase, $i l v I H$ acetolactate synthase, ilvC keto-acid reductoisomerase, $i l v D$ dihydroxy-acid dehydratase, kivd $\alpha$-ketoisovalerate decarboxylase, adh alcohol dehydrogenase
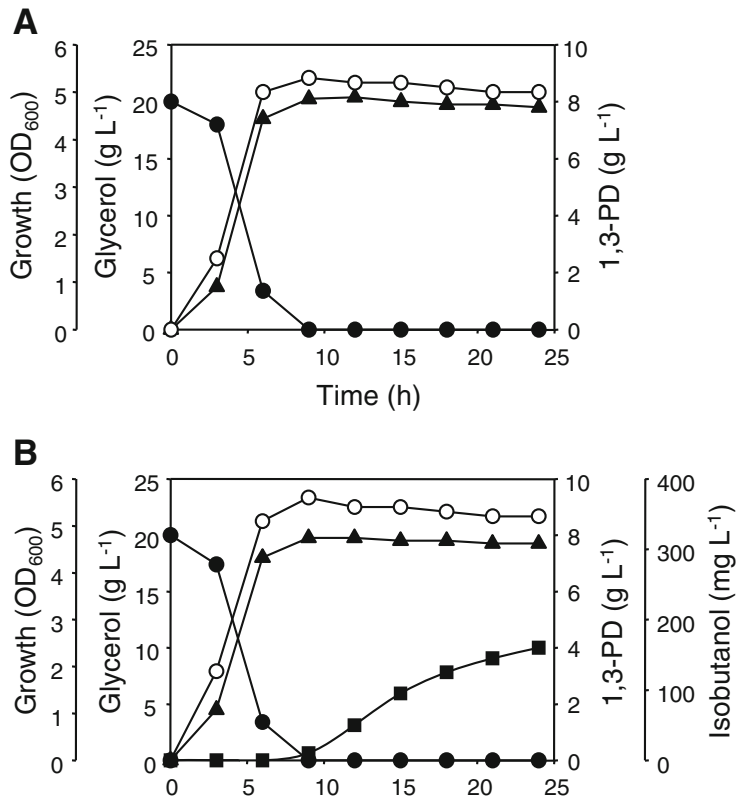

Fig. 2 Fermentation of $K$. pneumoniae $\Delta l d h A$ mutant harboring pBR322 (a) and pBR-iBO (b). Closed circles, residual glycerol levels; open circles, $\mathrm{OD}_{600}$ values; closed squares, isobutanol; closed triangles, 1,3-PD levels

inhibited in medium containing more than $1.3 \%$ (10.4 $\mathrm{g} \mathrm{l}^{-1}$ ) isobutanol (data not shown). Li et al. (2011) reported that growth of E. coli and C. glutamicum were also inhibited at this concentration of isobutanol. Although the isobutanol titer was low 
A

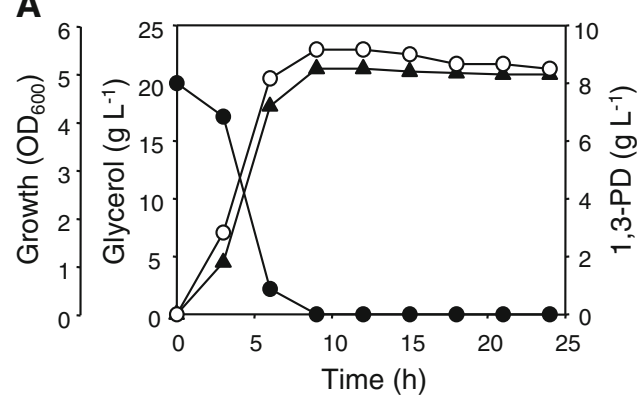

B

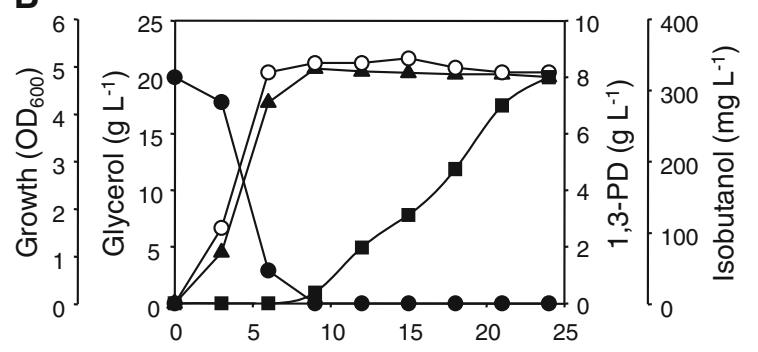

Fig. 3 Fermentation of $K$. pneumoniae $\Delta l d h A \Delta a d c$ mutant harboring pBR322 (a) and pBR-iBO (b). Closed circles, residual glycerol levels; open circles, $\mathrm{OD}_{600}$ values; closed squares, isobutanol; closed triangles, 1,3-PD levels

$\left(0.16 \mathrm{~g} \mathrm{l}^{-1}\right)$, to the best of our knowledge, this is the first report of microbial system constructed to produce isobutanol from glycerol, especially crude glycerol derived from the biodiesel industry.

Enhancement of isobutanol production

by elimination of the 2,3-BD biosynthesis pathway

Further genetic engineering was attempted to enhance the yield of isobutanol. Because 2,3-BD is another major product of the oxidative pathway of glycerol metabolism (Table 1), we constructed a 2,3-BD pathway-deficient $\Delta l d h A$ mutant strain harboring $\mathrm{pBR}-\mathrm{iBO}$ by inactivating the acetolactate decarboxylase gene $(a d c)$ via homologous recombination. Southern blotting confirmed correct insertion of the apramycin-resistance gene into the chromosomal $a d c$ gene (Supplementary Fig. 2). Consistent with the results of molecular analyses, 2,3-BD production was eliminated in the $\Delta l d h A$ $\Delta a d c$ mutant strain harboring pBR-iBO. Notably, isobutanol yield was improved twofold, from 160 to $320 \mathrm{mg}^{-1}$ (Fig. 3), demonstrating the ability of metabolic engineering to enhance isobutanol production from glycerol.
Genetic stability of the isobutanol-production trait

The stability of the plasmid pBR-iBO in the $K$. pneumoniae $\Delta l d h A \Delta b u d A$ mutant strain was examined. After batch fermentation of the recombinant strain for $20 \mathrm{~h}$, the cells were collected and cultivated on LB plates containing antibiotic. Colonies were then tested for maintenance of plasmid DNA by replica plating on medium with and without antibiotic. These experiments showed that $\mathrm{pBR}-\mathrm{iBO}$ was maintained in $96 \%$ of cells of the mutant strain (data not shown), indicating good genetic stability.

In the present work, a microbial system for producing of isobutanol from crude glycerol was constructed by genetic engineering $K$. pneumonia, which can produce 2,3-BD from glycerol (Oh et al. $2012 \mathrm{~b}$ ). The alteration of 2,3 BD biosynthesis pathway is promising and can lead to effective production of isobutanol from glycerol. This was accomplished by deleting competing pathways leading to biosynthesis of lactate and 2,3-BD and expressing genes (ilvIH, $i l v C$, ilvD, kivd and $a d h$ ) constituting the isobutanol biosynthesis pathway. This is first report of the production of isobutanol from a waste carbon source rather than from glucose.

Acknowledgments This work was supported by Korea Ministry of Environment and the Joint Degree and Research Center funded by Korea Research Council of Fundamental Science \& Technology.

\section{References}

Atsumi S, Hanai T, Liao JC (2008) Non-fermentative pathways for synthesis of branched-chain higher alcohols as biofuels. Nature 451:86-89

Cherepanov PP, Wackernagel W (1995) Gene disruption in Escherichia coli: $\mathrm{TcR}$ and $\mathrm{KmR}$ cassettes with the option of Flp-catalyzed excision of the antibiotic-resistance determinant. Gene 158:9-14

Connor MR, Liao JC (2011) Microbial production of advanced transportation fuels in non-natural hosts. Curr Opin Biotechnol 20:307-315

Curran KC, Leavitt JM, Karim AS, Alper HS (2013) Metabolic engineering of muconic acid production in Saccharomyces cerevisiae. Metab Eng 15:55-66

Datsenko KA, Wanner BL (2000) One-step inactivation of chromosomal genes in Escherichia coli K-12 using PCR products. Proc Natl Acad Sci USA 97:6640-6645

Durnin G, Clomburg J, Yeates Z, Alvarez PJJ, Zygourakis K, Campbell P, Gonzalez R (2009) Understanding and 
harnessing the microaerbobic metabolism of glycerol in Escherichia coli. Biotechnol Bioeng 103:148-161

Fournet-Fayard S, Joly B, Forestier C (1995) Transformation of wild type Klebsiella pneumoniae with plasmid DNA by electroporation. J Microbiol Meth 24:49-54

Gonzalez R, Murarka A, Dharmadi Y, Yazdani SS (2008) A new model for the anaerobic fermentation of glycerol in enteric bacteria: trunk and auxiliary pathways in Escherichia coli. Metab Eng 10:234-245

Lee WH, Seo SO, Bae YH, Nam H, Jin YS, Seo JH (2012) Isobutanol production in engineered Saccharomyces cerevisiae by overexpression of 2-ketoisovalerate decarboxylase and valine biosynthetic enzymes. Bioproc Biosyst Eng 35:1467-1475

Oh BR, Seo JW, Heo SY, Hong WK, Luo LH, Joe MH, Park DH, Kim CH (2011) Efficient production of ethanol from crude glycerol by a Klebsiella pneumoniae mutant strain. Bioresour Technol 102:3918-3922

Oh BR, Seo JW, Heo SY, Hong WK, Luo LH, Kim SH, Park DH, Kim CH (2012a) Optimization of culture conditions for 1,3-propanediol production from glycerol using a mutant strain of Klebsiella pneumoniae. Appl Biochem Biotechnol 166:127-137
Oh BR, Seo JW, Heo SY, Hong WK, Luo LH, Son JH, Park DH, Kim CH (2012b) Fermentation strategies for 1,3-propanediol production from glycerol using a genetically engineered Klebsiella pneumoniae strain to eliminate byproduct formation. Bioprocess Biosyst Eng 35:159-165

Oh BR, Hong WK, Heo SY, Luo LH, Kondo A, Seo JW, Kim $\mathrm{CH}$ (2013) The production of 1,3-propanediol from mixtures of glycerol and glucose by a Klebsiella pneumoniae mutant deficient in carbon catabolite repression. Bioresour Technol 130:719-724

Potera C (2009) Forging isobutanol with modified microbes. Gene Eng Biotechnol News 29:18-21

Smith KM, Liao JC (2011) An evolutionary strategy for isobutanol production strain development in Escherichia coli. Metab Eng 13:674-681

Strohl WR (2001) Biochemical engineering natural product biosynthesis pathway. Metab Eng 3:4-14

Zhanga K, Sawaya MR, Eisenberg DS, Liao JC (2008) Expanding metabolism for biosysthesis of nonnatural alcohols. Proc Natl Acad Sci USA 105:20653-22065 